\title{
«Lo inmediato y lo palpable»: música y erotismo en Concierto barroco, de Alejo Carpentier
}

\author{
Rodrigo GUIJARRO LASHERAS \\ rguijarr@ucm.es
}

\section{RESUMEN}

El erotismo desempeña en Concierto barroco (1974), de Alejo Carpentier, un importante papel que a veces se ha dejado de lado en favor de otros elementos más dominantes. Sin embargo, se da en esta novela una erotización de lo musical que implica una fusión -término clave para el análisis de cualquier aspecto de esta obra- de los atributos de ambos fenómenos. La jam session del capítulo quinto, así como el estatus simbólico que adquiere la trompeta, desempeñan un papel central en la articulación e imbricación de lo erótico-musical. Con todo ello, se pretende señalar que el erotismo es un factor clave para un más profundo análisis del texto, dada su condición de elemento conectado con los principales ejes temáticos que vertebran la novela.

Palabras clave: Concierto barroco, Alejo Carpentier, música, erotismo.

\section{«Lo Inmediato y lo Palpable»: Music and Eroticism in Alejo Carpentier's Concierto Barroco}

\begin{abstract}
Eroticism seems to play an important role in the analysis of Alejo Carpertier's novel Concierto Barroco (1974), although it has been frequently shelved in favour of other more dominant aspects. In addition, the existence of a continuous fusion of attributes assigned to music and eroticism should be highlighted. The interrelation of these two elements is particularly present in the «jam session» in chapter $\mathrm{V}$, as well as in the symbolic status conferred to the trumpet, establishing the core parts of the eroticmusic interdependence. The aim of the present analysis is to provide evidence that eroticism is an important and fully integrated element we should have in mind in order to approach to the heterogeneous kaleidoscope that conforms this novel.
\end{abstract}

Keywords: Concierto barroco, Alejo Carpentier, music, eroticism.

\section{Introducción}

El vínculo entre música y erotismo ha sido particularmente estrecho y constante a lo largo de los siglos. La primera siempre ha parecido poseer un carácter erotizante 
que a menudo se ha llegado a considerar lúbrico y lascivo: desde el canto de las sirenas hasta Le poème de l'extase de Scriabin, pasando por la zarabanda, prohibida bajo el reinado de Felipe II, el desarrollo de Occidente nos ofrece toda una historia cultural de lo erótico a través de la música. Alejo Carpentier, novelista con amplios conocimientos sobre música y atento a las posibilidades que esta pudiera ofrecer de cara a la creación literaria, logra aunar, con gran inventiva, música, erotismo y literatura en Concierto barroco (1974), una de sus obras más representativas. El objeto de este trabajo es, pues, analizar cómo el autor cubano imprime un sello particular y dota de gran relevancia hermenéutica a esta relación músico-erótica.

Por su parte, Concierto barroco ha gozado de una abundante y sostenida atención crítica desde su mismo momento de publicación. Especial interés han suscitado su 'escritura musical', esto es, su imitación formal de la música ${ }^{1}$, así como la visión que plantea el texto de la identidad cultural mestiza del continente america$\mathrm{no}^{2}$. Otro elemento muy destacado para la interpretación de la novela, no obstante, es la fuerte presencia del erotismo, sobre el que, quizás por más obvio o más trivial en apariencia, apenas ha recaído la atención. Es, como pretendemos mostrar, un aspecto plenamente integrado en la propuesta estética del autor cubano que merece ser comentado en detalle.

\section{Lo erótico en Concierto barroco}

Este análisis puede partir de una sencilla constatación: en Concierto barroco, todo erotismo se ve siempre asociado a la música. Ya la primera escena nos presenta un encuentro sexual acompañado de madrigales entre el Amo y su visitante nocturna. Francisquillo, el sirviente, canta para ellos mientras la situación adquiere tintes netamente sexuales: «La visitante nocturna se puso las tetas al fresco, mientras la mano del Amo se le extraviaba entre los encajes de las enaguas, buscando el calor de la segrete cose cantada por el Dante» (Carpentier 2011: 169). Cuando Francisquillo acaba de interpretar su ah, dolente partita, ya no encuentra al Amo y a su visitante, que, siendo la víspera de la partida, se han ido a la cama a «oficiar los júbilos de la despedida» (Carpentier 2011: 171).

Esta primera escena es más importante de lo que podría parecer. Recordemos que la novela comienza con marcadas figuras de repetición centradas en el término «plata», que reaparece de diversas formas durante todo el capítulo. Esto constituye un caso de word music, tal y como Scher (1968: 3-5) primero, Wolf (1999: 58) después, lo han definido. Se trata de una forma de imitación literaria de la música que pasa por acentuar la dimensión del significante entendido en su dimensión puramente sonora. Se puede generar así un ritmo, una sonoridad, una glosolalia que, si bien nunca será música, sí se aproxima a ella, la imita.

${ }^{1}$ Chang (2002) y Rubio Navarro (1999) son tal vez los estudios más completos hasta la fecha en cuanto a la presencia musical en esta obra.

2 Vid. Figueroa Sánchez (2007) y Fama (1988) para una aproximación a esta cuestión. 
De este modo, Concierto barroco parece abrirse como si de una obra musical se tratara -tal y como su título anuncia-: «De plata los delgados cuchillos, los finos tenedores; de plata los platos donde un árbol de plata [...]» (Carpentier 2011: 165), generando repeticiones y recurrencias más propias de una obra musical que de una novela. Pero no es nuestro objetivo analizar el funcionamiento de los mecanismos imitativos de la música en este texto, sino mostrar cómo música y erotismo establecen unos lazos particularmente estrechos y significativos a lo largo de la obra. Al final del capítulo, cuando la tensión erótica entre el Amo y la visitante, a la que ha contribuido el madrigal interpretado por Francisquillo, se resuelve con la escapada de ambos a la cama, la aliteración argéntea reaparece con un carácter conclusivo:

Pero, cuando el servidor concluyó el madrigal, apartando la mirada del mástil de la vihuela, se vio solo: ya el Amo y su visitante nocturna habían marchado a la habitación de los santos en marcos de plata para oficiar los júbilos de la despedida en la cama de las incrustaciones de plata, a la luz de los velones puestos en altos candelabros de plata. (Carpentier 2011: 171)

La reaparición de «plata», término fundamental elegido para construir la imitación musical, acompaña al madrigal y a la vihuela del servidor y subraya de este modo el carácter erótico del texto. Tenemos así dos elementos musicales adheridos al encuentro sexual entre los dos personajes: por un lado, una tematización musical, de carácter diegético - puesto que tiene lugar dentro de la historia-, que propicia e incita al encuentro sexual (los madrigales de Francisquillo) y, por otro lado, una imitación musical extradiegética que se recuerda justo en el momento en el que se consuma dicho encuentro (la aliteración de "plata», que subraya la dimensión sonora, acústica del texto). El erotismo parece así superar el marco de lo narrado e impregnar también la propia narración.

Por si este comienzo no fuera lo suficientemente significativo, música y erotismo reaparecen continuamente en los siguientes capítulos: Scarlatti se queja de que, durante las representaciones operísticas, no es inhabitual que las parejas se pongan a «fornicar en los palcos», aun durante el momento más trágico de la obra (Carpentier 2011: 193); el rasgo más prominente de Anna Giró, querida de Vivaldi que representa el primer papel en la ópera que este estrena, le lleva a recibir el sobrenombre de «la alemana»: «por algo la llaman 'la alemana' -dice el negro-: y usted sabe que, en eso de las ubres, las alemanas...» (Carpentier 2011: 213). En otro momento, se comenta, a propósito de Scarlatti, que «cada cual tiene sus debilidades. Porque, a este, le ha dado siempre por las mujeres» (Carpentier 2011: 227). No es, desde luego, un rasgo que singularice al compositor napolitano frente a otros personajes. Todos ellos hallan un momento general de esparcimiento en el carnaval veneciano que se celebra cuando el Amo llega a la ciudad. Como es esperable, este se convierte en la excusa perfecta para un relajamiento de costumbres que, en la novela que nos ocupa, pasa, claro está, por la desinhibición sexual: «las damas decentes se libraban de cuantas obscenidades y cochinas palabras se habían guardado en el alma durante meses, en tanto que los maricones [...] aflautaban el tono de sus proposiciones, que no siempre caían en el vacío» (Carpentier 2011: 190). 
No obstante, parece difícil concluir que el carnaval sea el recurso que dé vía libre a que afloren las desinhibiciones, y con ellas el erotismo y el desenfreno sexual. No le hace falta a Carpentier, dado el planteamiento de la novela, recurrir al carnaval para plasmar una sexualidad omnipresente en la acción y en la narración. Por ello, el capítulo cuarto -el del carnaval- no supone, a nuestro juicio, una «liberación del erotismo» (Nogueira Peredo 2004: 95) más allá de un nivel puramente accesorio que corresponde a las «damas decentes» a las que se alude, toda vez que el erotismo ya está plenamente liberado desde los primeros compases de la novela.

Por otra parte, Carpentier hizo acompañar la primera edición de la novela ${ }^{3}$ de un paratexto muy llamativo, a saber, las numerosas ilustraciones a modo de frontispicio o cornisa que flanquean el texto en todo momento. Es interesante reparar en cómo estos paratextos apoyan algunos de los principales temas y rasgos del libro: el barroquismo prosístico del autor cubano, por ejemplo, se refleja a través de un marcado horror vacui, del abigarramiento y el predominio de líneas curvas y sinuosas, entre otros rasgos (figuras 1 y 2). Estos dibujos contienen, además, una imaginería netamente musical cargada a menudo de un carácter erotizante. La máscara de un sátiro junto con una flauta de pan (Carpentier 2011: 222), motivo que aparece en otra de las ilustraciones junto a una lira (Carpentier 2011: 210), más instrumentos musicales, tañidos esta vez por unos ambiguos ángeles desnudos (Carpentier 2011: 175) que, páginas después (Carpentier 2011: 192), adoptan posturas deliberadamente equívocas son otras de las imágenes que subrayan los elementos de Concierto barroco en los que centramos nuestro análisis.

Dentro de este universo saturado de erotismo, tiene una particular relevancia la ciudad, que protagoniza otro de los temas fundamentales del texto: la idea de viaje. La novela se concibe como un viaje cuyas distintas ciudades de paso aparecen sistemáticamente definidas por las posibilidades sexuales que ofrecen. Todas las ciudades se caracterizan en términos de su oferta sexual y musical. Así, en la estancia del Amo en Venecia, llega un punto en que «ya me jode esta ciudad, con sus canales y gondoleros. Ya me he tirado a la Ancilla, la Camilla, la Zulietta, la Angeletta, la Catina, la Faustolla, la Spina, la Agatina, y otras muchas cuyos nombres he olvidado -iy basta! Regreso a lo mío esta misma noche» (Carpentier 2011: 226). El agotamiento y hartazgo de la ciudad se concibe y expresa, una vez más, en términos netamente sexuales.

Otro tanto sucede con La Habana, en la que «cerradas estaban las casas de baile, de guaracha y remeneo, con sus mulatas de carnes ofrecidas bajo el calado de los encajes almidonados» (Carpentier 2011: 174); o con París, a la que Filomeno, por primera vez, acudirá para hacerse un nombre respetable y no por «las hembras» (Carpentier 2011: 228). Pero el ejemplo más destacado lo proporciona Madrid, en la medida en la que, al contrario que las anteriores, es una ciudad antierótica. Esto se plasma, como no podía ser de otro modo, en sus mujeres y en su música:

${ }^{3}$ Cfr. Carpentier (1974). Citamos, no obstante, por la edición crítica de 2011, que también las incluye. 
Una noche, fueron de putas a una casa donde los recibió una ama obesa, ñata, bizca, leporina, picada de viruelas, con el cuello envuelto en bocios, cuyo ancho trasero, movido a palmo y medio del suelo, era algo así como el de una enana gigante. Rompió la orquesta de ciegos a tocar un minué de empaque lagarterano. [...] El Amo, seguido por una chusma de mendigos [...], no cesaba en sus lamentos contra la ruindad de esta villa harto alabada [...] donde un caballero de su mérito y apostura tenía que aliviarse con putas. (Carpentier 2011: 184-185)

En el Madrid de Carpentier, los apetitos se satisfacen de una forma monótona e incluso sórdida. Esto afecta no solo a la sexualidad y a las «músicas que si mucho divertían al negro por la novedad, bastante disgustaban al Amo por lo destempladas» (Carpentier 2011: 183), sino también a la comida, otro de los motivos recurrentes que sirve para caracterizar lugares y situaciones. Así, se yuxtaponen las quejas culinarias a las musicales y a las sexuales para concluir, finalmente, continuar el viaje hacia Italia, donde las perspectivas son mejores. Lo erótico y lo antierótico construyen, así, una línea divisoria que distingue los múltiples lugares recreados en la novela.

Visto esto, parece claro que puede afirmarse la existencia de un estrecho vínculo entre música y erotismo. La música acompaña siempre a la manifestación de la sexualidad, la estimula, la propicia. Además, ambas funcionan como elemento de caracterización de las distintas etapas del viaje y de la ciudad que se visita. No obstante, las relaciones entre ambos no acaban aquí: una de las escenas más importantes -la que constituye el capítulo quinto-, así como uno de sus símbolos más recurrentes y destacados, la trompeta, se construyen con la hábil disposición de música y erotismo.

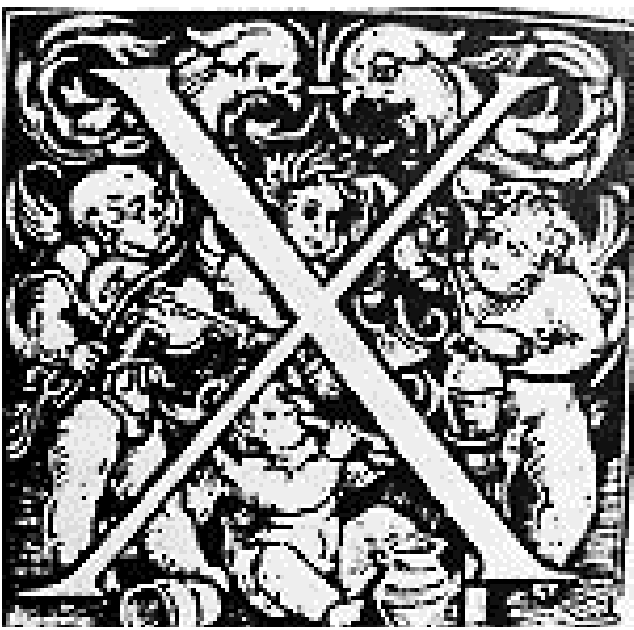

Figuras 1 y 2: Ilustraciones de Concierto barroco (Carpentier 2011: 175 y 192).

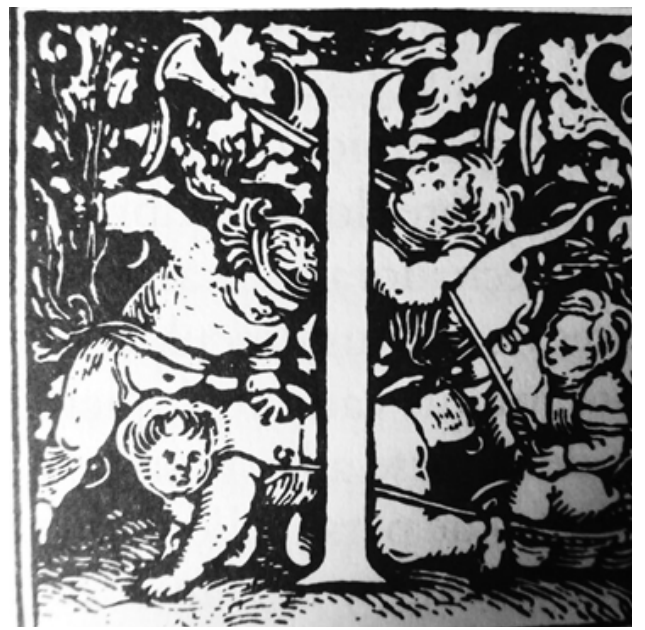




\section{La jam session}

Quizás la escena que mejor fusiona erotismo y música sea la que corresponde a la «jam session $\rangle^{4}$ (Carpentier 2011: 207) que ocupa el capítulo quinto. El Amo y el negro llegan a Venecia, donde conocen a Vivaldi ${ }^{5}$, Haendel y Scarlatti. Todos ellos acaban esa noche en el Ospedale della Pietà, habitado por jóvenes huérfanas entrenadas en el arte musical bajo las órdenes del Pelirrojo. Las bellas y púdicas jóvenes que salen al encuentro de los visitantes reciben un apellido en correspondencia con el instrumento que tocan (Pierina del violino, Cattarina del corneto, Bettina della viola, etc.), lo cual no es asunto baladí e implica una nueva fusión de lo erótico y lo musical: «Los nombres de estas se fueron reduciendo al del instrumento que tocaban. Como si las muchachas no tuviesen otra personalidad, cobrando vida en sonido, las señalaba con el dedo» (Carpentier 2011: 196).

Lo primero que hacen las anfitrionas es procurar abundante comida y bebida, anticipando así el carácter dionisiaco de la velada. La música desata un frenesí al que las setenta jóvenes y los tres grandes compositores, a los que se une Filomeno con unas improvisadas cacerolas a modo de tambores, se entregan. El léxico erotizante inunda la descripción de la música que tocan: «tremebundo impulso», «estremecidas por un escándalo del cielo», «frenético allegro», «fabuloso ímpetu», «juego concertante» (Carpentier 2011: 197-198). A ello se le añade, poco después, la contemplación de un cuadro en el que la serpiente tentadora le ofrece a Eva la fruta prohibida, lo cual puede verse desde esta perspectiva como símbolo del desenfreno musical y erótico al que se acaban de entregar. Esto lleva a Filomeno a desencadenar un nuevo mantra extático basado en el «sonsonete cien veces repetido» «Kabala-sum-sum-sum» (Carpentier 2011: 199), que concluye con una conga frenética y climática, monjas incluidas, por todo el Ospedale.

Pese a todo lo comentado, no se hallan en esta escena tantas alusiones sexuales explícitas como las que sazonan el resto de los capítulos. Puede mencionarse alguna relativa excepción como el caso de Scarlatti, quien «se echó una última copa al gaznate, y, agarrando por la cintura a Margherita del Arpa Doble, se perdió con ella en el laberinto de celdas del Ospedale della Pietá» (Carpentier 2011: 201). Mucho más perspicaz es, sin embargo, la referencia al lesbianismo de las muchachas, quizás más bien una fantasía de los personajes masculinos que, en ese momento, son espectadores de la acción:

${ }^{4}$ El empleo de este término para calificar el concierto y las improvisaciones a las que se entregan Vivaldi, Haendel y Scarlatti refleja un recurso importante en la obra: el uso deliberado del anacronismo, lo que contribuye a la dislocación temporal y la particular concepción del tiempo que construye la novela. Pueden consultarse, para el análisis de la jam session, Burgos (2005), centrado en el eje espacio-temporal del texto, o Norcisa López (2004), quien desarrolla una particular concepción del «contrapunto» musical que Carpentier aplicaría como método compositivo.

${ }^{5}$ La figura histórica de Vivaldi se emplea también en esta novela para potenciar el aspecto lúdico-festivo de su carácter que habitualmente se le ha atribuido. En este sentido, puede verse Peñalta Catalán (2015). 
A falta de caballeros, pues Antonio no bailaba y los demás descansaban en la hondura de sus butacas, se formaron parejas de oboe con tromba, clarino con regale, cornetto con viola, flautino con chitarrone, mientras los violini piccoli alla francese se concertaban en cuadrillas con los trombones. «Todos los instrumentos revueltos - dijo Jorge Federico [...]». (Carpentier 2011: 201)

Se trata de una plasmación de lo erótico más sutil, en donde el desenfreno de la música parece sugerir el desenfreno en otros aspectos, si bien esta fusión músico-erótica es justamente lo que le confiere al capítulo un mayor poder de persuasión. Es por ello por lo que la propuesta musical de Concierto barroco no puede deslindarse del erotismo que satura sus páginas. Carpentier sitúa la música -erotizada- en el centro de su propuesta. Si esta contribuye a una concepción del tiempo que numerosos estudios se han ocupado de desentrañar ${ }^{6}$, el erotismo potencia su sentido de lo inmediato e instantáneo y la ruptura de la linealidad temporal que la caracteriza.

\section{La trompeta como símbolo}

Entre los distintos pasajes en los que la música cobra protagonismo, destaca la presencia de un instrumento que alcanza un estatus simbólico notorio: la trompeta. En primer lugar, la trompeta se concibe como prenda de amor que Cattarina del Corneto le regala a Filomeno para que la recuerde. Esto subraya las implicaciones eróticas de la jam session -muestra que en su transcurso se han generado fuertes atracciones entre sus participantes-, además de configurar una dimensión simbólica de dicho instrumento que se ve consolidada en los siguientes capítulos. Si antes se erotizaba a las jóvenes mediante su fusión con el instrumento que tocaban, ahora se erotiza la trompeta en virtud de su vínculo con Cattarina del Corneto.

A partir de este momento, la trompeta reaparece constantemente, y su papel simbólico se consolida ${ }^{7}$. No analizaremos aquí todas las ocasiones en las que se menciona dicho instrumento, si bien es interesante señalar que con frecuencia aparece en un contexto erotizado: «jaquí la gente se acuesta con todo Dios! Pero déjeme escuchar la música, pues está sonando un pasaje de trompeta que mucho me interesa» (Carpentier 2011: 214). La trompeta representa el erotismo de la fusión, de la amalgama -con las implicaciones que esto tiene en lo que toca a la identidad americana-, de ahí su relevante papel en la ópera americana de Vivaldi, en el jazz y en el concierto de Louis Armstrong con el que concluye Concierto barroco. La trompeta, también, representa una particular vivencia del tiempo: es «la percepción de lo

${ }^{6}$ El ya citado estudio de Nogueira Peredo (2004) es un buen ejemplo de ello.

${ }^{7}$ El simbolismo de la trompeta ha sido estudiado por Fabrice Parisot (2012), quien señala la revolución musical y rítmica que dicho instrumento implica, así como la revolución política que proyecta hacia el futuro (Parisot 2012: 239), ya que «anuncia los actos de liberación y los movimientos de independencia» (Parisot 2012: 243). Sobre esta base, nuestro estudio pretende aportar al análisis la dimensión erótica que también posee el instrumento en cuestión. 
inmediato y palpable» (Carpentier 2011: 231), sintagma que, significativamente, se aplica tanto a la trompeta de Armstrong como a las nalgas de la acomodadora. En este sentido, puede considerarse emblema del lugar común hacia el que música y erotismo apuntan en esta novela.

La trompeta es el instrumento de la severidad del juicio final, la «Biblia hecha ritmo» (Carpentier 2011: 230), instrumento «de malas pulgas y palabras mayores» (Carpentier 2011: 229). Pero es también la «música terrenal» que le interesa a Filomeno, ese «cobre impar» del jazz que protagoniza el concierto final, así como el arrebato «místico y triunfal» (Carpentier 2011: 232) que esta supone. La trompeta une la jam session veneciana, las jóvenes músicas, la obra de Haendel, la ópera de Vivaldi y el jazz de Louis Armstrong. Es un hilo de Ariadna que une épocas y momentos muy alejados entre sí que en la novela se yuxtaponen sin solución de continuidad. Uno de los momentos en los que esta dimensión simbólica del instrumento se plasma con mayor nitidez corresponde a la escena del cementerio, en donde el impulso erótico de la trompeta entra en contraste con los muertos que reposan bajo las lápidas. La música que sale de este instrumento es, se nos dice, impropia para un lugar tal, «por respeto a los difuntos que tan quietos yacían» (Carpentier 2011: 208). El pleonasmo «tan quietos» enfatiza justamente el contraste entre el estatismo de los muertos y el dinamismo palpable y sensual de la prenda de amor que Cattarina del Corneto ha entregado.

\section{Conclusiones}

Así, parece claro que lo erótico queda relacionado con los principales elementos temáticos y formales de Concierto barroco. El erotismo no se trata (solo) de algo meramente recreativo. Tampoco pretende adquirir tintes de provocación epatante, ni poseer la función de brindar un descanso o recreo al lector. Se trata, en cambio, de algo plenamente imbricado en el entramado temático del texto. En este sentido, puede decirse que lo que la word music hace en un plano formal, el erotismo lo hace en un plano temático.

Podemos así considerar el erotismo de dos modos: es, por un lado, una determinada forma de tematizar y abordar el deseo e impulso sexual que se correlaciona de forma especialmente estrecha con la música y sus atributos. Pero también, por otro, el resultado de la combinación de lo anterior y el barroquismo e imitación musical que plantea la novela; una determinada forma de placer estético que el lector experimenta a consecuencia de la cooperación de todos los elementos de la obra.

En conclusión, hay, en primer lugar, una omnipresencia de lo erótico a lo largo de todo Concierto barroco. Además, las situaciones con un contenido sensual o sexual están sistemáticamente asociadas a la música, pilar fundamental del texto. El capítulo quinto se muestra especialmente relevante desde esta perspectiva: es en la jam session donde la fusión entre erotismo y música alcanza su punto álgido, de tal manera que esta última adquiere las propiedades de lo primero, haciéndose, como las nalgas de la acomodadora que atrae a Filomeno, «inmediata y palpable». Asimismo, esta concepción de lo erótico se materializa en un símbolo clave: la trom- 
peta, que articula los saltos cronológicos de la historia. Concierto barroco es una obra compleja, heterogénea, que admite y ha recibido multitud de análisis desde muy diversas perspectivas. En este caleidoscopio no debemos soslayar, sin embargo, la importancia del erotismo en la construcción del discurso musical que temática y formalmente plantea el texto.

\section{Bibliografía}

Burgos, Fernando (2004): «Concierto barroco: escenarios del tiempo». Inti: Revista de literatura hispánica, núm. 59-60, pp. 61-76.

CARPENTIER, Alejo (1974): Concierto barroco. México D.F.: Siglo XXI.

- (2011): Concierto barroco. Madrid: Akal.

Chang, Leiling (2002): «Una novela musical: Concierto barroco, de Alejo Carpentier», en Silvia Alonso (ed.), Música y literatura: estudios comparativos y semiológicos, pp. 149186. Madrid: Arco Libros.

FAMA, Antonio (1988): «Cultura, historia e identidad en Concierto barroco, de Alejo Carpentier». Revista de Crítica Literaria Latinoamericana, núm. 14, pp. 129-138.

FIGUEROA SÁNCHEZ, Cristo Rafael (2007): «Concierto barroco: memoria cultural americana e identidad mestiza como figuraciones neobarrocas», en Barroco y neobarroco en la literatura hispanoamericana. Cartografias literarias de la segunda mitad del siglo XX, pp. 142-155. Medellín: Editorial Universidad de Antioquía / Editorial Pontificia Universidad Javeriana.

Nogueira Peredo, Fátima (2004): «Acerca del tiempo y de la historia en Concierto barroco». Inti: Revista de literatura hispánica, vol. 59, pp. 91-104.

NorCisA LóPEZ, Adolfo (2004): «Concierto barroco: contrapunto entre el espacio central apolíneo y el espacio marginal dionisiaco». Revista de Estudios Hispánicos, vol. 31, núm. 1, pp. 171-182.

PARISOT, Fabrice (2012): «Des trompettes de Jéricho aux trompettes de la Renommée: itinéraire d'un instrument symbolique dans Concert baroque d'Alejo Carpentier», en Carmen Vásquez y Kevin Perromat Augustin (eds.), Hommage à Alejo Carpentier (1904-1980), pp. 225-244. París: Indigo / Université de Picardie Jules Verne.

Peñalta CATAlán, Rocío (2015): «Vivaldi como personaje de ficción en Concierto barroco de Alejo Carpentier, Stabat Mater de Tiziano Scarpa y Settecento de Marcos Calveiro». Madrygal, vol. 18, núm. especial, pp. 233-242.

Rubio NaVArro, Gabriel María (1999): Música y escritura en Alejo Carpentier. Alicante: Publicaciones de la Universidad de Alicante.

ScHER, Steven Paul (1968): Verbal Music in German Literature. New Haven: Yale University Press.

Wolf, Werner (1999): The Musicalization of Fiction. A Study in the Theory and History of Intermediality. Ámsterdam / Atlanta: Rodolpi. 